\title{
Does the more internet usage provide good academic grades?
}

\author{
V. Senthil ${ }^{1}(D)$
}

Received: 20 January 2018 / Accepted: 28 May 2018 / Published online: 6 June 2018

(C) The Author(s) 2018

\begin{abstract}
The Internet is an unavoidable resource to students for their day today academic activities and it is now occupies a central role in any academic environment. Student's academic references have changed dramatically in the recent years. The present day students spending more time on internet and their reading and reference style is changed drastically from the traditional methods. Many students have replaced their text books, reference books and daily newspapers with online editions. The internet behaviours such as data usage (upload, download) and visiting number of websites to their positive (or negative) effect on Cumulative Grade Point Average (CGPA) are analysed in this paper. The sample data in an academic environment is used in this research to elicit the impact on their academic performance. Both descriptive and inferential statistical methods are applied in this research and the research results indicated that internet usage has a marginal impact on students' academic performance.
\end{abstract}

Keywords Internet usage behaviour - Technology impact analysis · Internet browsing pattern

\section{Introduction}

During the last decade, the academic infrastructure has become digital with increased interconnections among products, processes and services. The internet is now occupies a central role in any academic environment. Student's academic references have changed dramatically in the recent years. The present day students spending more time on internet and their reading and reference style is changed drastically from the traditional methods. Many have replaced their daily newspapers, text and reference books with online editions. The internet is helping the students to search the academic

V. Senthil

veersenthil@gmail.com

1 Thiagarajar School of Management, Thirupparankundram, Madurai, Tamilnadu, India 
content more easily and efficiently than ever before. Students may employ the internet in an educational matters such as writing paper, searches for answers to questions and preparing for assignments and others. However on the flip side, time spent in activities where surfing the internet occurs could substitute away from time allocated to reading, studying and completing homework, this may hurt the student's academic performance. The internet consist of so many diverse functions, it is also common for students to spend more time on various non-academic activities such as shopping online, emailing friends, playing online games, online auctions, and others. In contrast to normal internet users, students addicted to the Internet had problems falling asleep, lower habitual sleep efficiency, poorer sleep quality, more sleep disturbances and daytime dysfunction and used sleep medication more frequently (Cheung and Wong 2011). Students who use the internet until late into the night would find themselves plagued by excessive sleepiness the next day which depletes them of their energy and mental agility in studying.

The internet is registering a huge and rapid growth and this growth is exposed to continue at significant rates at a global scale. The expansion is explained by the tremendous impact of the internet on the economic, financial, social, political systems as well as at the individual level. Practically, the internet has become part of billons of people's daily life. The studies performed on internet use topic revealed the positive and negative aspects of internet use. As positive aspects of the internet use, the authors (Stancis and Tinca 2014) retained the facilitation of communication easiness of information retrieval and sharing, the internet being appreciated as an excellent medium for knowledge transfer, new effective way of running business cultural and social gains etc.,.

This research paper is tries to investigate whether the more usage of internet provide good academic grades to students or to know the impact of internet on the academic performance to students in a Business School setup. And this paper is an exploratory study of analysing how the internet usage such as data usage (upload, download) and number of websites visited are helpful (or not helpful) to achieve the academic excellence by students. This paper is organized as follows, the section 2 explains the background literature, section 3 describes the research methodology, and section 4 shows the research findings and final section with the conclusion.

\section{Literature review}

Tabatabaei and Gardiner (2012) studied that online learning has experienced strong growth in recent years. Institutions of higher education are continuing to expand their offerings of online courses and degrees, thereby encouraging students to enrol in online courses. Hypothetical Information Systems graduates education mode (online versus traditional studies) influences their employment judgments. Weill and Woernar (2013) studied that digital models are transparent to all and students can learn quickly, because switching costs in the digital world are often lower than in the physical world. Kubey et al. (2011) uses a survey study of 572 students at a public university and find that heavy internet use is highly correlated with poor academic performance. Leuven et al. (2004) concluded that there is no evidence for a relationship between increased 
educational use of Internet and Communication Technology (ICT) and students' performance. In fact, they find a consistently negative and marginally significant relationship between ICT use and some student achievement measures. Mbaeze et al. (2010) study results indicated that there was no statistically significant relationship between ICT and students' academic performance. Sampath Kumar and Manjunath (2013) demonstrated that the high use of the internet services by teachers and researchers in university setup, most of them used internet in support of their study and teaching. Fu and Chen (2009) emphasized that surfing on internet for course material has positive net effect on intellectual development and vocational preparation in addition to personal development. Oskouei (2010) attempt to get better insights on how Internet usage behaviours of female students in university can effect on their different academic activities and also compare usage patterns of different department students. The author also attempts to find the relationships between Internet usage pattern of female students and their academic performance CPI (Cumulative Performance Index). The same author Oskouei (2010) identifies percentage of users visited academic-websites along with their time spent in these categories of websites. Tsitsika et al. (2009) note that the female gender is negatively associated with excessive internet usage. Spennemann (2007) looks at the assumption of 24/7 web usage by analysing the $\log$ files of 9 university servers in Australia, and concludes that the majority of traffic (81\%) happens between the work hours (08.00 to 18.00) with another peak taking place around 21.00 .

On one hand, some studies suggest that the internet provides tremendous educational benefits, such as more information access, better visual intelligence skills, and enhancement of teacher-student communications. On the other hand, many negative impacts are also listed in literature. Qiaolei (2014) studied that on internet addiction revealed numerous symptoms shared by other forms of addictions, including substance-based addictions. Andrew D. Madden et al. (2006) explains the amount the child's ability to explore the virtual environment. Research by Cao et al. (2011) has suggested that excessive internet use can be pathological and addictive. Griffiths (2000) consider Internet Addiction (IA) to be a kind of technological addiction such as computer addiction and one of a subset of behavioural addiction. Usman et al. (2014) identified the relationship between Internet Addiction (IA) and academic performance among foreign undergraduate students in Malaysia. The study results showed that there were no significant differences in IA in term of cumulative Students' Academic Performance (SAP). Tao et al. (2010) has stated that symptoms of IA include pre-occupation, withdrawal, loss of control and functional impairment. Similarly Turel et al. (2011)

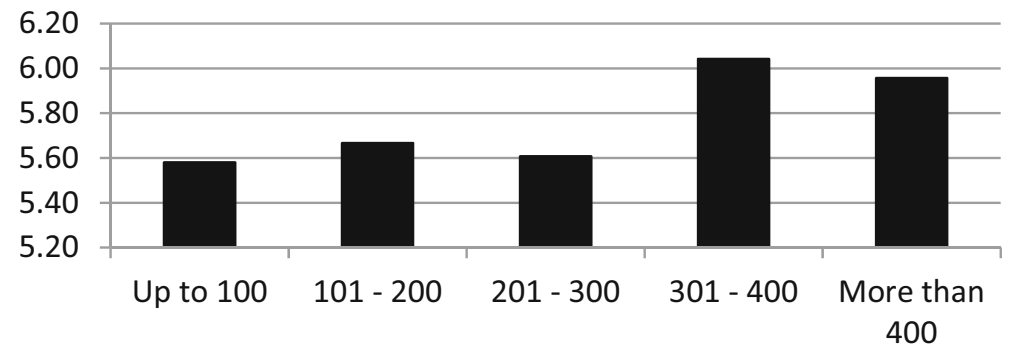

Fig. 1 Number of websites visited and average CGPA 


\section{Total Data Usage}

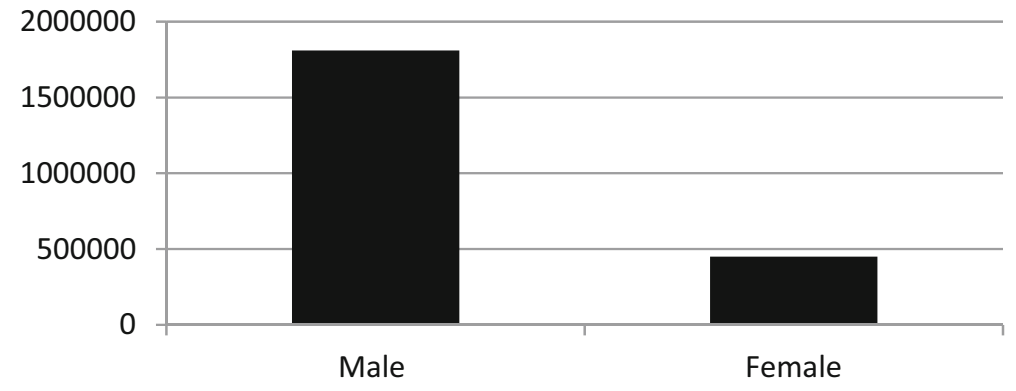

Fig. 2 Gender based data usage

has found additional symptoms of IA which include negative personal, societal and work place related ramifications. Although there is no universal agreement on the definition of IA, the literature indicates uncontrolled excessive use of internet. Sandeep Grover et al. (2010) emphasize that the adverse consequence of internet use can affect interpersonal, social, occupational, psychological and physical domains of individuals life. Derbyshire et al. (2013) reveal that problems associated with frequent internet use include an inability to control the time spent on internet and poor academic performance.

Anderson et al. (2012) finds that excessive social networking is detrimental to fulfilling other obligations and interferes with sleeping hours, resulting in a postponement of bedtimes and rising times. Awan and Khan (2016) explains the phenomenon of the internet addiction has been approved from a medical and psychological point of view, which often treat it as a behavioural disorder. Chou et al. (2005) studied the internet addiction since 1996 and noted that the focus has been on online activities choice, social-psychological factors such as sensation seeking, pleasure experience, loneliness, and depression and other computer user related issues. Chen and Peng (2008) find out that students who use the internet excessively have significantly lower university grades, social relations and learning satisfaction, compared with the normal internet usage. Also, students who use the internet excessively

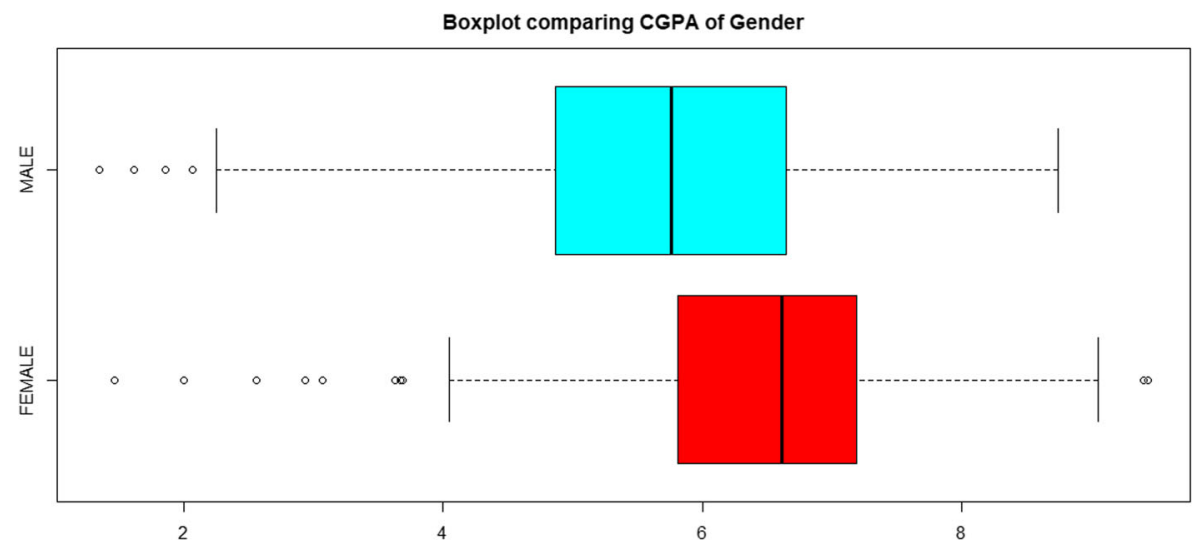

Fig. 3 CGPA and gender 
Table 1 Gender based internet usage

Group statistics

\begin{tabular}{llllll}
\hline & Gender & N & Mean & Std. deviation & Std. error mean \\
\hline \multirow{2}{*}{ Dud } & Female & 145 & 3097.99 & 4606.50 & 382.55 \\
& Male & 318 & 5691.59 & 5699.82 & 319.63 \\
\hline
\end{tabular}

are more likely to be depressed, physically ill, lonely and introverted. Bankole et al. (2017) explains the loss of interest in academic, which leads to a decreased academic performance and a deterioration of the relationship with teachers. Lim et al. (2002) studied that employees are more likely to rationalize their misuse of the internet in the workplace when they perceive that their employers do not treat them fairly. From the previous literature it was found that the impact of ICT on performance of students in higher education is not clear, and there are contradictory results in the earlier literature.

\section{Research methodology}

The objective of this research is to identify the student's internet use skills and to understand their behaviour of using internet. The student internet log data in an academic environment is used in this research to elicit the impact on their academic performance. The research by Austin and Totaro (2011) is taken as a base to this research. The primary objective of this research is an exploratory study of how the behaviour of internet use is helpful (not helpful) for students to achieve the high academic performance. This paper aims to answer the research questions such as, Is the Internet Usage behaviour has any relationship with Academic Performance? And does the more data usage provides high academic grades?. The assumption of this study is students having more data usage and visiting more number of websites are having a positive effect on their Cumulative Grade Point Average (CGPA). The assumed hypotheses are as follows,
$H_{1}$ : There is a significant relationship between data usage with CGPA.
$\mathrm{H}_{2}$ : There is a significant relationship between numbers of websites visited with CGPA.
$\mathrm{H}_{3}$ : There is a significant relationship between Gender with CGPA.
$H_{4}$ : There is a significant relationship between Data Usage, Gender with CGPA.
$\mathrm{H}_{5}$ : There is a significant relationship between Data Usage and Gender with CGPA.

Table 2 Linear regression method to model 3 model summary

\begin{tabular}{lllll}
\hline Model & $\mathrm{R}$ & R square & Adjusted R square & Std. error of the estimate \\
\hline 1 & $.24^{\mathrm{a}}$ & .06 & .058 & 1.37 \\
\hline
\end{tabular}

${ }^{\text {a }}$ Predictors: (Constant), Gender 
Table 3 ANOVA ${ }^{\mathrm{a}}$ method to model 3

\begin{tabular}{llccccc}
\hline Model & & Sum of Squares & df & Mean Square & F & Sig. \\
\hline 1 & Regression & 54.89 & 1 & 54.89 & 29.25 & $.000^{\mathrm{b}}$ \\
& Residual & 865.09 & 461 & 1.88 & & \\
& Total & 919.98 & 462 & & & \\
\hline
\end{tabular}

${ }^{a}$ Dependent Variable: CGPA

${ }^{\mathrm{b}}$ Predictors: (Constant), Gender

The following are the mathematical models (Eqs. 1, 2, 3, 4 and 5) in which the Cumulative Grade Point Average (CGPA) are function of exogenous factors such as Data Usage (DUD), Number of Websites Visited (NOWV) and Gender.

$$
\begin{gathered}
C G P A=\beta_{0}+\beta_{1} * D U D+\varepsilon \\
C G P A=\beta_{0}+\beta_{1} * N O W V+\varepsilon \\
C G P A=\beta_{0}+\beta_{1} * \text { Gender }+\varepsilon \\
C G P A=\beta_{0}+\beta_{1} * D U D+\beta_{2} * \text { Gender }+\varepsilon \\
C G P A=\beta_{0}+\beta_{1} * D U D+\beta_{2} * \text { Gender }+\beta_{3} * D U D * \text { Gender }+\varepsilon
\end{gathered}
$$

\section{Data analysis and results}

The detailed research analysis is not evident or scarce in the literature on the Indian context. Descriptive statistics is used to identify the characteristics of the respondent's internet usage profile. Using SPSS to run Regression and ANOVA tests are used to determine the differences between the groups. The data set of residential students from a reputed school is taken for research analysis whose internet usage behaviour (463 samples) are taken for the data analysis. There are different types of devices are used for internet use, Mobile Phones are the highest usage of device by the students but Laptops are also highly used because of its suitability for almost all type of academic activities. The students who is visiting more number of websites (300 to 400 websites) have slightly higher CGPA (6.04) than the students visiting less number of websites (up to

Table 4 Linear regression method to model 4 model summary

\begin{tabular}{lllll}
\hline Model & $\mathrm{R}$ & R Square & Adjusted R square & Std. error of the estimate \\
\hline 1 & $.250^{\mathrm{a}}$ & .063 & .059 & 1.36921 \\
\hline
\end{tabular}

a Predictors: (Constant), dud, Gender 
Table 5 ANOVA $^{\text {a }}$ method to model 4

\begin{tabular}{lllllll}
\hline Model & & Sum of squares & df & Mean square & F & Sig. \\
\hline 1 & Regression & 57.597 & 2 & 28.799 & 15.361 & $.000^{\mathrm{b}}$ \\
& Residual & 862.378 & 460 & 1.875 & & \\
& Total & 919.975 & 462 & & & \\
\hline
\end{tabular}

${ }^{a}$ Dependent Variable: CGPA

${ }^{\mathrm{b}}$ Predictors: (Constant), dud, Gender

100 websites, CGPA = 5.58), i.e. the students who are curious to learn the new ideas, concepts and techniques are visiting more number of websites as shown in Fig. 1. Data download is having more negative relationship with the CGPA than the Data Upload, this may be because of non-academic activities such as online gaming, music downloads, sports watching and other leisure activities done by the students. The research result also evidenced that the internet usage pattern is high among the Male students comparing to the Female students. The Fig. 2 shows the total data usage for a week period of time in Mega Bytes (MB) by the Male and Female group of students. The Gender Behavior on Internet usage is evidenced that the Data Usage (DUD) by Male group of students is very high comparing to the female group. This may be because of more deviation of attention by male groups or may be because of the focused attention by the female group as shown in Fig. 3 and in Table 1.

The Linear Regression Method (LRM) is applied to Model 1 (Eq. 1) where CGPA is dependent variable and DUD is independent variable. The $\mathrm{R}^{2}$ value to model 1 is 0.00 i.e. there is no relationship between data usage and CGPA, and so $\mathrm{H}_{1}$ is rejected. The LRM is applied to Model 2 (Eq. 2) where the CGPA is dependent variable and the Number Of Websites Visited (NOWV) is independent variable. The $\mathrm{R}^{2}$ value is 0.05 and it is not statistically significance, so $\mathrm{H}_{2}$ is rejected. The Tables 2 and 3 shows the

Table 6 Correlations between the variables in Model 5

\begin{tabular}{llllll}
\hline & & CGPA & Dud & Gender & dud_Gender \\
\hline CGPA & Pearson Correlation & 1 & .000 & $-.244^{* * *}$ & -.044 \\
& Sig. (2-tailed) & & .993 & .000 & .349 \\
\multirow{5}{*}{ Dud } & $\mathrm{N}$ & 463 & 463 & 463 & 463 \\
& Pearson Correlation & .000 & 1 & $.219^{* *}$ & $.964^{* * *}$ \\
& Sig. (2-tailed) & .993 & & .000 & .000 \\
Gender & $\mathrm{N}$ & 463 & 463 & 463 & 463 \\
& Pearson Correlation & $-.244^{* *}$ & $.219^{* *}$ & 1 & $.366^{* *}$ \\
& Sig. (2-tailed) & .000 & .000 & & .000 \\
dud_Gender & $\mathrm{N}$ & 463 & 463 & 463 & 463 \\
& Pearson Correlation & -.044 & $.964^{* *}$ & $.366^{* *}$ & 1 \\
& Sig. (2-tailed) & .349 & .000 & .000 & \\
& $\mathrm{~N}$ & 463 & 463 & 463 & 463 \\
\hline
\end{tabular}

**Correlation is significant at the 0.01 level (2-tailed) 
Table 7 Model 5 summary

\begin{tabular}{|c|c|c|c|c|c|c|c|c|c|}
\hline \multirow[t]{2}{*}{ Model } & \multirow[t]{2}{*}{$\mathrm{R}$} & \multirow[t]{2}{*}{ R Square } & \multirow{2}{*}{$\begin{array}{l}\text { Adjusted R } \\
\text { square }\end{array}$} & \multirow{2}{*}{$\begin{array}{l}\text { Std. error of } \\
\text { the estimate }\end{array}$} & \multicolumn{5}{|l|}{ Change statistics } \\
\hline & & & & & $\mathrm{R}$ square change & F change & df1 & $\mathrm{df} 2$ & Sig. F change \\
\hline 1 & $.251^{\mathrm{a}}$ & .063 & .057 & 1.37 & .063 & 10.26 & 3 & 459 & .000 \\
\hline
\end{tabular}

Dependent Variable: CGPA

${ }^{\text {a }}$ Predictors: (Constant), dud_Gender, Gender, dud

Linear Regression and ANOVA output of Model 3 where the CGPA is dependent variable and Gender is an independent variable. The $\mathrm{R}^{2}$ values is 0.06 , $(6 \%$ of the variance is explained by the model) and model is statistically significant where the $p$ value is $<\alpha$, so retain $\mathrm{H}_{3}$.

The Tables 4 and 5 shows the Linear Regression and ANOVA results of Model 4 where CGPA is independent variable and DUD, Gender is independent variables. The $\mathrm{R}^{2}$ value is 0.063 and the model is statistically significant so $\mathrm{H}_{4}$ is retained.

The Multiple Linear Regression method is applied to model 5, where CGPA is a dependent variable and Data Usage, Gender and interaction between Data Usage and Gender are independent variables. The Table 6 shows the correlation values of these variables and the Tables 7 and 8 shows the Regression and ANOVA results with interaction effect. The results show that the model is statistically significant so $\mathrm{H}_{5}$ is retained. Fig. 4 shows the normal PP plot of regression standardized residuals with interaction effect.

In this paper five research models are proposed to study the internet usage behaviour and CGPA received by the students. As per the research results, there is no direct relationship between Data Usage with CGPA and also to Number of Websites Visited with CGPA i.e. the first and second models are failed to achieve the specified hypothesis. The remaining three models are statistically significant but their $\mathrm{R}^{2}$ values are very small, so there is a marginal relationship between the Gender and data usage with the CGPA.

\section{Conclusion}

In this study, how the internet usage behaviours are helpful to achieve the high academic performance for the students are analysed. The internet behaviours such as

Table 8 ANOVA

\begin{tabular}{lllllll}
\hline Model & & Sum of squares & df & Mean square & F & Sig. \\
\hline 1 & Regression & 57.832 & 3 & 19.277 & 10.263 & $.000^{\mathrm{a}}$ \\
& Residual & 862.143 & 459 & 1.878 & & \\
& Total & 919.975 & 462 & & & \\
\hline
\end{tabular}

Dependent Variable: CGPA

${ }^{\text {a }}$ Predictors: (Constant), dud_Gender, Gender, dud 


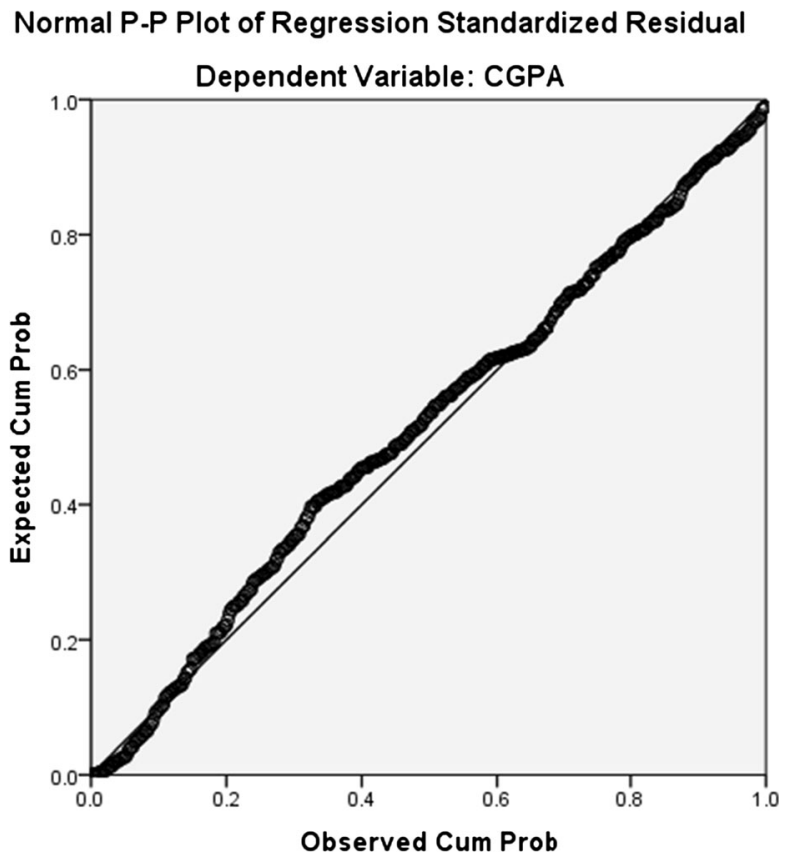

Fig. 4 Normal PP Plot of regression standardized residual

Data Usage, Number Of Websites Visited, Gender are analysed with CGPA. As per our research results, there is a marginal relationship among the variables. The limitation of this study is restricted to only one campus of students thus generalization of findings to the entire population is limited. The focus on students as the sample study also limits the generalization of this study's findings across other segments of society. Also Indian students work culture is different from other parts of the world which is not analysed here. The cross sectional data are analysed here, the longitudinal data will be taken as future research work. This is an early effort of study about the internet usage behaviour and academic performance and the study offers valuable insights to the academicians and researchers.

Open Access This article is distributed under the terms of the Creative Commons Attribution 4.0 International License (http://creativecommons.org/licenses/by/4.0/), which permits unrestricted use, distribution, and reproduction in any medium, provided you give appropriate credit to the original author(s) and the source, provide a link to the Creative Commons license, and indicate if changes were made.

\section{References}

Anderson, B., Fagan, P., Woodnutt, T., \& Chamorro-Premuzic, T. (2012). Facebook psychology: Popular questions answered by research. Psychology of Popular Media Culture, 1, 23-37.

Austin, W., \& Totaro, M. W. (2011). High school students academic performance and internet usage. Journal of Economics and Economic Education Research, 12(1), 41-54.

Awan, M.A. \& Khan, H.U. (2016) Status of internet addiction among college students: a case of South Korea, first american academic research conference on global business, economics, finance and social sciences, New York, USA. 
Bankole, O.A. Lalitha, M., Khan, H.U., Jingo (2017) Information technology in the maritime industry past, present and future: Focus on long carriers, 7th IEEE International Advance Computing Conference, Hyderabad, India, (Conference Proceeding).

Cao, H., Sun, Y., Wan, Y., Hao, J., \& Tao, F. (2011). Problematic internet use in Chinese adolescents and its relation to psychosomatic symptoms and life satisfaction. BMC Public Health, 11, 802.

Chen, Y.-F., \& Peng, S. S. (2008). University students' internet use and its relationships with academic performance, interpersonal relationships, psychosocial adjustment, and self-evaluation. Journal of Cyber psychological Behaviour, 11(4), 467-469. https://doi.org/10.1089/cpb.2007.0128.

Cheung, L.M., Wong W.S. (2011) The effects of insomnia and internet addiction on depression in Hong Kong Chinese adolescents: an exploratory cross-sectional analysis. Journal of Sleep Research, 20(2), 311-7. https://doi.org/10.1111/j.1365-2869.2010.00883.

Chou, C., Condron, L., \& Belland, J. (2005). A review of the research on internet addiction. Educational Psychology Review, 17(4), 363-388.

Derbyshire, K. L., Lust, K. A., Schreiber, L. R., Odlaug, B. L., Christenson, G. A., Golden, D. J., \& Grant, J. E. (2013). Problematic internet use and associated risks in a college sample. Elsevier Journal of Comprehensive Psychiatry, 54(5), 415-422.

Fu, Y. C., \& Chen, S. Y. (2009). Internet use and academic achievement: Gender differences in early adolescence. Adolescence 2009 Winter, 44(176), 797-812.

Griffiths, M. D. (2000). Does internet and computer "addiction" exist? Some case study evidence. Cyber Psychology and Behavior, 3, 211-218.

Grover, S., Chakraborty, K., \& Basu, D. (2010). Industrial Psychiatry Journal, 19(2), 94-100.

Kubey, R. W., Lavin, M. J., \& Barrows, J. R. (2011). Internet usage and collegiate academic performance decrements: Early findings. Journal of Communications, 51(2), 366-382.

Leuven, E., Lindahl, M., Oosterbeek, H., \& Webbink D. (2004), The effect of extra funding for disadvantaged pupils on achievement, available at http://ftp.iza.org/dp1122.pdf (accessed 04 Jan. 18).

Lim (2002). The IT way of loafing on the job: Cyberloafing, neutralizing and organizational justice. Journal of Organizational Behavior, 23(5), 675-694.

Madden, A. D., Ford, N. J., Miller, D., \& Levy, P. (2006). Children's use of the internet for informationseeking: What strategies do they use, and what factors affect their performance? Journal of Documentation, 62(6), 744-761.

Mbaeze, C., Ukwandu, E., \& Andu, C. (2010). The influence of information and communication technologies on students' academic performance. Journal of Information Technology Impact, 10(3), 129-136.

Oskouei, R.J. (2010) Behaviour mining of female students by analyzing log files. In Fifth International Conference on Digital Information Management (ICDIM), Thunder Bay.

Qiaolei, J. (2014). Internet addiction among young people in China. Emerald Journal of Internet Research, 24(1), 2-20.

Sampath Kumar, B. T., \& Manjunath, G. (2013). Internet use and its impact on the academic performance of university teachers and researchers: A comparative study. Emerald Journal of Higher Education, Skills and Work-Based Learning, 3(3), 219-238.

Spennemann, D. (2007), Learning and teaching 24/7: Daily internet usage patterns at nine. Australian Universities, International Journal of Information and Learning Technology, (Campus-Wide Information Systems), v24 n1 p 27-44.

Stancis, V., \& Tinca, A. (2014). A critical look on the student's internet use - An empirical study. Journal of Accounting and MIS, 13(4), 739-754.

Tabatabaei, M., \& Gardiner, A. (2012). Recruiters perceptions of information system graduates with traditional and online education. Journal of Information Systems Education, 23(2), 133-141.

Tao, R., Huang, Wang, J., Zhang, H., Zhang, Y., \& Li, M. (2010). Proposed diagnostic criteria for internet addiction. Addiction, 105, 556-564.

Tsitsika, A., Critselis, E., Kormas, G., Filippopoulou, A., Tounissidou, D., Freskou, A., Spiliopoulou, T., Louizou, A., Konstantoulaki, E., \& Kafetzis, D. (2009). Internet use and misuse: A multivariate regression analysis of the predictive factors of internet use among Greek adolescents. European Journal of Paediatric., 168(6), 655-665. https://doi.org/10.1007/s00431-008-0811-1.

Turel, O., Serenko, A., \& Giles, P. (2011). Integrating technology addiction and use: An empirical investigation of online auction users. MIS Quarterly, 35(4), 1043-1061.

Usman, N. H., Alavi, M., \& Shafeq, S. M. (2014). Relationship between internet addiction and academic performance among foreign undergraduate students. Procedia-Social and Behavioral, 4th World Conference on Phychology, Counseling and Guidance, 114, 845-851.

Weill, P., \& Woernar, S. L. (2013). Optimizing your digital business model. MIT Slogan Management Review, 54(3), 71-78. 